\title{
DEVELOPMENT, OPTIMIZATION AND EVALUATION OF PULSATILE DRUG DELIVERY CAPSULES LOADED WITH CARVEDILOL BY APPLYING QUALITY BY DESIGN
}

\author{
BHARATH KUMAR A. ${ }^{*}$, GIRENDRA KUMAR GAUTAM ${ }^{2}$, SYED SALMAN B. ${ }^{3}$
}

1Department of Pharmaceutics, Bhagwant University, Sikar Rd, Ajmer, Rajasthan 305004, India, ${ }^{2}$ Department of Pharmaceutical Chemistry, Shri Ram College of Pharmacy, Muzaffarnagar, Uttar Pradesh 251001, India, ${ }^{3}$ Department of Pharmaceutics, Mahathi College of Pharmacy, CTM Cross Road, Madanapalle, 517325, Andhra Pradesh, India Email: bkreddy9479@gmail.com

Received: 16 Sep 2021, Revised and Accepted: 25 Nov 2021

\begin{abstract}
Objective: The purpose of this research is to find the best way for designing carvedilol pulsatile drug delivery system capsules.

Methods: The research paves the way to improve the method of preparing carvedilol pulsatile drug delivery by adjusting critical material attributes (CMA) such as coating polymer concentration, critical process parameters (CPP) such as inlet temperature and atomizing air pressure, and their impact on critical quality attributes (CQA) like particle size (PS in $\mathrm{nm}$ ), entrapment efficiency in percentage (\% EE) and amount of drug delivered in percent (\%ADR) at $12 \mathrm{~h}$ in the carvedilol pulsatile pellets filled capsules by applying the BOX-BEHNKEN design. By varying the polymer
\end{abstract} concentration and process parameters, nearly 15 formulations were created.

Results: Based on the influence of CMA, CPP on CQA, the formulation CP13 was determined to be the most optimized formulation among the 15 formulations. The optimized levels of CMA were found to be- 1 level of coating polymer concentration and CPP was found to be- 1 level of inlet temperature, 0 level of atomizing air pressure and it optimized CQA like PS was found to be $1017.5 \pm 8.4 \mathrm{~nm}, \%$ EE was found to be $96.8 \pm 2.8 \%, \%$ $\mathrm{ADR}$ at $12 \mathrm{~h}$ was found to be $88.4 \pm 3.4 \%$. Carvedilol Pulsatile drug delivery system was designed by using optimized fluidized bed coater in order to decrease the usage of attributes, decrease the productivity cost and enhance the usage of specific attributes at fixed concentration for further manufacturing scale.

Conclusion: By the current results it was concluded that the optimized CMA and CPP that shown in the results are the suitable attributes for the best formulation of carvedilol pulsatile drug delivery system capsules.

Keywords: Carvedilol, Pulsatile, Particle size, Capsules, Pharmacokinetic etc

(C) 2022 The Authors. Published by Innovare Academic Sciences Pvt Ltd. This is an open access article under the CC BY license (https://creativecommons.org/licenses/by/4.0/) DOI: https://dx.doi.org/10.22159/ijap.2022v14i1.43146. Journal homepage: https://innovareacademics.in/journals/index.php/ijap

\section{INTRODUCTION}

The circadian behavior of the disease helps to release the drug in a pulsatile form, which may release the drug at a particular time. Pulsatile forms of drug delivery systems are achieving a lot of attention as they deliver the required concentration of drug at a particular time interval, which will enhance the therapeutic effect at particular time. A pulsatile drug delivery system is defined as the delayed or fastens the release of drug in pulsatile form, which releases a certain amount of active pharmaceutical ingredients molecule at a pre-determined release period. Thus, these systems are designed based on the body circadian cycle [1].

To understand the circadian rhythm of the disease, first we need to understand chrono-pharmacotherapy or chronotherapeutics. This term 'chrono' refers to the observation that each and every anabolic and catabolic action goes through the rhythmic alteration in time. Many hormonal, metabolic and other functions of the body's vary considerably in a day. These variations in body system reason alteration in diseased state and in the concentration of drug plasma. Blood pressure and heart rate of the body are elevated between 6.00 am to 12.00 noon due to circadian rhythm of hormone release. Many diseases follow circadian rhythm for example, hypertension, arthritis, peptic ulcer, asthma, neurological disorder, cancer, diabetes, hypercholesterolemia etc. Some of the above diseases are worse during the day for example, osteoarthritis, while some of them are worse in the evening and nights during sleep, for example, cough [2].

Physical, chemical and biological properties must be given due consideration in the selection of components and processing steps for the dosage form. The final product must be one that meets not only the requirements placed on it from a bioavailability standpoint, but also the practical mass production criteria of process and product reproducibility. While undergoing formulation, it should be understood the theoretical formulation and target processing parameters, as well as the ranges for each excipients and processing parameter. The optimization technique provides both the depth of understanding and an ability to explore and defend ranges for the formulation and processing factors. With the rational approaches to the selection of the several excipients and manufacturing steps for a given product, one qualitatively selects a formulation. Optimization was a useful tool for quantifying a formulation that could be qualitatively determined. The word optimize is defined as follows i.e., to make as perfect, effective and functional as possible [3].

In developing a dosage form, one must undergone logical steps, carefully controlling the variables, and changing one at a time until a satisfactory system is produced. No matter how the dosage form is designed, but the trial and error method will improve the quality of the dosage form [4].

Carvedilol acts as a beta-adrenoceptor blocker which, on blocking the receptors, it reduces the heart rate and force of contraction. Carvedilol also blocks adrenergic receptors in the arteries and causes the arteries to relax and the blood pressure to fall. The bioavailability of carvedilol was found to be $25-35 \%$ and its protein binding was found to be $98 \%$. The carvedilol will be metabolized in the liver (CYP2D6, CYP2C9) with the elimination half-life of 7-10 h and nearly $16 \%$ of the drug was excreted in the urine. $60 \%$ of the drug was excreted in feces, shows that the only concentration of carvedilol was available to systemic circulation to give a therapeutic effect. Morning hypertension has recently attracted more attention because of the close relationship between blood pressure levels in the early morning and cardiovascular risk. Cases of morning hypertension, i.e., higher blood pressure in the early morning than in the evening, are classified into two types: the 'Morning surge'. Cases of morning hypertension, i.e., higher blood pressure in the early morning than in the evening, are classified into two types: the "morning-surge" type, characterized by a marked increase in blood 
pressure in the early morning, and the "nocturnal-hypertension" type, characterized by high blood pressure that persists from nighttime until early morning. Although these two types are caused by different pathologic mechanisms, both result in hypertensive organ damage and an increase in cardiovascular risk. Control of morning hypertension can be regarded as the gateway of strict $24 \mathrm{~h}$ blood pressure control. Standard antihypertensive treatment, in accord with current guidelines, when combined with chronobiologic antihypertensive treatment focused on morning hypertension and guided by home blood pressure monitoring, seems to provide more effective prevention of cardiovascular events [5-9].

The main objective of this research covers the development of oral pulsatile drug-delivery systems loaded with carvedilol drug an emphasis on time-controlled drug-release systems. And also to determine the Critical Material Attributed (CMA) and Critical Process Parameter (CPP) and their effect of Critical Quality attribute for the formulation of the pulsatile drug delivery system.

\section{MATERIALS AND METHODS}

Carvedilol obtain as a gift sample from Aurobindo Pvt ltd., Hyderabad, India. Polyvinyl pyrolidone, Aerosil, HPMC K4M, Ethylcellulose, Kollicoat, Eudragit L 100 was received from Himedia Pvt. Ltd. Mumbai. All the other solvents used in this project belong to analytical grade.

\section{Formulation of carvedilol pulsatile drug delivery system}

The composition of carvedilol pulsatile drug delivery system capsules as shown in table 1 . The core layer consists of a sugar bead in the size range of 59.5 to $80.5 \mu \mathrm{m}$. Over the core layer, properly prepared drug solution with water-soluble release controlling and wetting polymer (polyvinyl pyrolidone-PVP K-30) was coated with the help of fluidized bed coater (Umang coater, Wurster insert, Umang Ltd, Mumbai, India) with the following parameters like 1.0 $\mathrm{mm}$ nozzle needle, $50{ }^{\circ} \mathrm{C}$ drying temperature, 2-5 psi atomizer pressure, $1 \mathrm{ml} / \mathrm{min}$ atomizer flow rate. After drying of a drug layer over the sugar bead, HPMC K4M seal coat solution was sprayed and dried. Further, different type of control release coating polymer was coated with various concentrations [10-15]

\section{Preparation of drug-containing pellets}

Carvedilol-loaded pellets were prepared by layering a drug-binder solution $(10 \% \mathrm{w} / \mathrm{w})$ on to sugar beads using a fluidized bed coater (Umang coater, Wurster insert; Umang Ltd, Mumbai, India). Dispersion of Carvedilol and polyvinyl pyrollidone (PVP K-30) was sprayed using the bottom spray mode. Layered beads were dried at $40{ }^{\circ} \mathrm{C}$ for 5-10 min. The detailed composition of drug layering and polymer coating is given in table 1 and the process parameter of the drug layering processes and coating are given in table 1,2 [16-19].

Table 1: Composition of drug loading and polymer coating

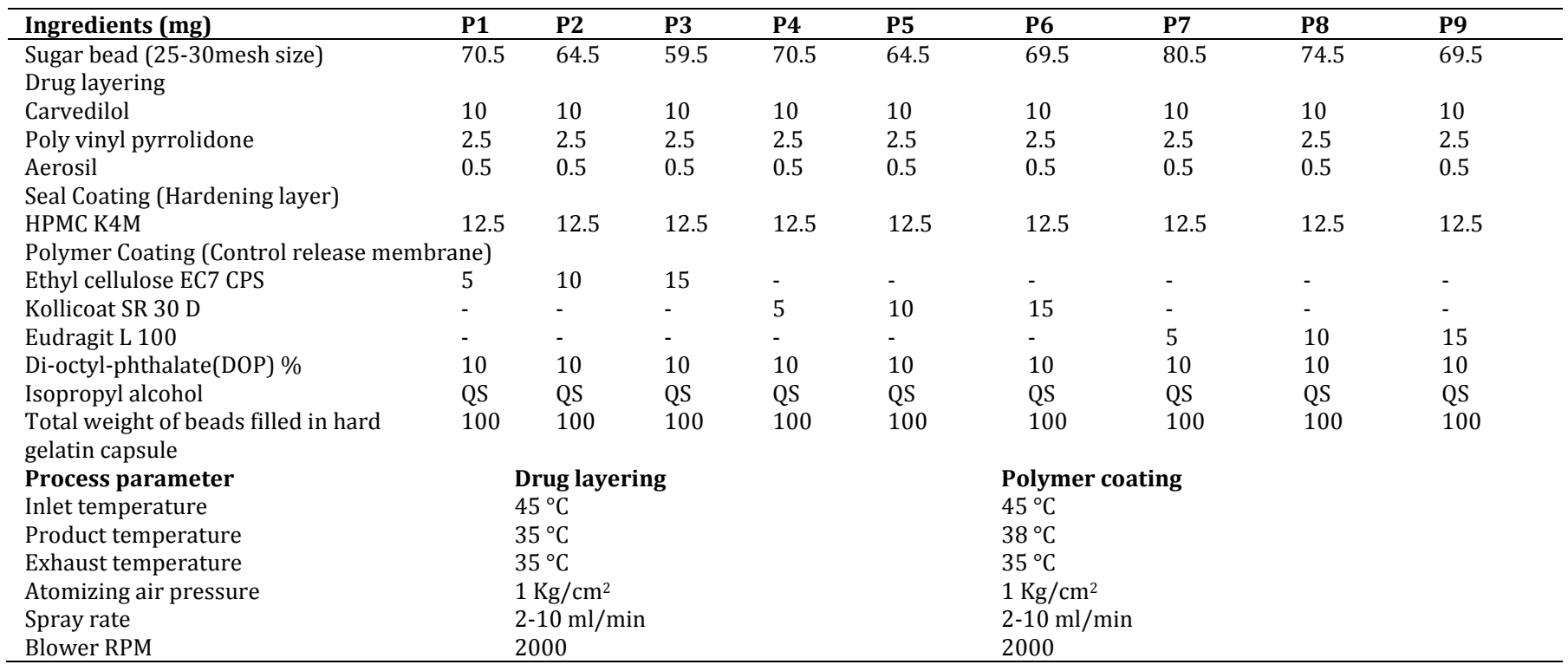

Table 2: Optimization design for preparation of carvedilol pulsatile drug delivery tablet

\begin{tabular}{|c|c|c|c|c|}
\hline \multirow{2}{*}{ Run } & \multicolumn{4}{|c|}{ Critical product and process parameter (level/conc. or range) } \\
\hline & Pattern & Conc. of EC (mg) & Inlet temperature $\left({ }^{\circ} \mathrm{C}\right.$ ) & Atomizing air pressure $\left(\mathrm{kg} / \mathrm{cm}^{2}\right)$ \\
\hline CP1 & $0-+$ & $0 / 5$ & $-1 / 40$ & $1 / 1.5$ \\
\hline CP2 & ++0 & $1 / 7.5$ & $1 / 45$ & $0 / 1$ \\
\hline CP3 & $0++$ & $0 / 5$ & $1 / 45$ & $1 / 1.5$ \\
\hline CP 4 & $0+-$ & $0 / 5$ & $1 / 45$ & $-1 / 0.5$ \\
\hline СР 5 & +-0 & $1 / 7.5$ & $-1 / 40$ & $0 / 1$ \\
\hline $\mathrm{CP} 6$ & $+0+$ & $1 / 7.5$ & $0 / 43$ & $1 / 1.5$ \\
\hline CP 7 & 000 & $0 / 5$ & $0 / 43$ & $0 / 1$ \\
\hline CP 8 & 000 & $0 / 5$ & $0 / 43$ & $0 / 1$ \\
\hline СР 9 & $-0+$ & $-1 / 2.5$ & $0 / 43$ & $1 / 1.5$ \\
\hline CP 10 & $0--$ & $0 / 5$ & $-1 / 40$ & $-1 / 0.5$ \\
\hline СР 11 & -+0 & $-1 / 2.5$ & $1 / 45$ & $0 / 1$ \\
\hline CP 12 & $+0-$ & $1 / 7.5$ & $0 / 43$ & $-1 / 0.5$ \\
\hline СР 13 & --0 & $-1 / 2.5$ & $-1 / 40$ & $0 / 1$ \\
\hline СР 14 & $-0-$ & $-1 / 2.5$ & $0 / 43$ & $-1 / 0.5$ \\
\hline CP 15 & 000 & $0 / 5$ & $0 / 43$ & $0 / 1$ \\
\hline \multicolumn{2}{|c|}{ Critical Quality Attribute } & Particle size (nm) (Y1) & Entrapment Efficiency \% Y2) & $\%$ amt. of drug release at $12 \mathrm{~h}(\mathrm{Y} 3)$ \\
\hline \multicolumn{2}{|c|}{ Constraints } & Minimize & Maximize & Maximize \\
\hline
\end{tabular}




\section{Coating of the drug layered pellets}

The drug layered pellets were coated in a fluidized bed coater using the bottom spray mode (Umang coater, Wurster insert, Umang Ltd, Mumbai, India) with a plasticized non-aqueous solution of polymer (ethylcellulose EC 7 CPS, Kollicoat SR 30D, Eudragit L 100)) at different coating levels each respectively. The polymer solution was plasticized with DOP $(10 \% \mathrm{w} / \mathrm{v}$, based on the mass of the polymer). The non-aqueous solvents Isopropyl alcohol (IPA) was used as dissolving polymers. The polymer content of the plasticized dispersion was then adjusted to $25 \%$. The final coating solution was sprayed onto drug-loaded sugar beads to achieve a weight gain of $10 \%$. The process parameters for the coating step are given in table 1 [20-22].

\section{Optimization of attributes by box-behnken design}

The selected pre-optimized attributes were fixed in Box Behnken Optimization Design (BBD) as shown in table 2, was designed with the help of JMP QbD software. 15 formulation runs were generated. BBD of Response Surface Methodology with 15 formulation runs was used to determine the effects of changes in the Critical Quality Attribute (CQA) like Particle size (nm), \% Entrapment Efficiency, \% amount of drug release at $12 \mathrm{~h}$ corresponding to the Critical product and process parameter like Concentration of EC (Thickness of the coat), Inlet temperature, Atomizing air Pressure. In this optimization QbD design, the implementation of a first-order response surface model and elucidation of the effect outcome was based on a box-behnken design. Selected CMA and CPP from pre-optimization parameters are given as $\mathrm{X} 1$ for Concentration of EC; X2 for Inlet temperature in degree celcius; $\mathrm{X} 3$ for atomizing air pressure $\left(\mathrm{kg} / \mathrm{cm}^{2}\right)$ at 3-different levels code as low $(-1)$, medium $(0)$ and high $(+1)$. By using the above attributes, the Pulsatile pellets was formulated and determined the effect on CQA like Y1-Particle size in mm, Y2-\% Entrapment efficiency and Y3-\% amount of drug release $[23,24]$.

\section{Drug and excipients compatibility studies-differential scanning calorimetry (DSC) analysis}

DSC studies were used to determine the melting point of samples. It helps to report about the Purity of the drugs; Compatibility between drugs and Excipients. DSC studies were carried out for Carvedilol, PVP K30, HPMC K4M, Ethylcellulose EC7 CPS, Kollicoat SR 30 D, Eudragit L 100, Di-octyl phthalate (DOP) and drug-loaded pulsatile pellets in the DSC Schimadzu model instrument. Approximately the samples were weighed as $5 \mathrm{mg}$ and heated in aluminum pans at a temperature of $20-200{ }^{\circ} \mathrm{C}$ at the rate of $20^{\circ} \mathrm{C} /$ min using dry nitrogen as the effluent gas. Melting point readings were given in the form of exothermic or endothermic peak [22].

\section{Particle size determination}

The average particle size of the lipid particulate dispersions was determined using a Nanopartica SZ 100 particle size analyzer (Horiba, Japan). The sample dispersion was diluted in 1:9 v/v with double-distilled water to ensure that the light scattering intensity was within the instrument's sensitivity range. Double-distilled water was filtered through $0.45 \mu \mathrm{m}$ membrane filters (Pall Life sciences, Mumbai, India) prior to particle size determination [25].

\section{Surface morphology}

The surface morphology of the pulsatile pellets for the selected optimized formulation was observed by the Scanning Electron Microscope (Hitachi S-3000N). Pulsatile pellet samples were coated with platinum of $600 \AA$ using a sputter coater and examined through SEM. Coated pellets were then mounted on a sample holder and scanned through an electron beam. The electron beam strikes the pellets and emits secondary electrons based on the nature of the surface, which gives the surface morphology image of the pellets [26, 27].

\section{Entrapment efficiency}

Encapsulation efficiency was determined by Centrifugation method. In this study, $1 \mathrm{ml}$ of pellets dispersion was taken in dialysis bags (Himedia) with a molecular weight of 12,000-14,000 Daltons with $2.4 \mathrm{~nm}$ pore size. The prepared dialysis membrane bag was taken into the centrifuge tube. This centrifuge tube was properly filled with $9 \mathrm{ml}$ of $\mathrm{pH} 7.4$ phosphate buffer and centrifuged at 15,000 rpm for $1 \mathrm{~h}$ in REMI centrifuge in order to extract the free drug from the pellets. After $1 \mathrm{~h}, 5 \mathrm{ml}$ of sample was withdrawn from the phosphate buffer saline. The drug concentration of the withdrawn sample was determined by UV Spectrophotometer at $240 \mathrm{~nm}$ for Carvedilol against blank solution. The blank solution was prepared by using the same technique with the same ingredients but without the drug. The analysis was done in triplicate $(n=3)$. Percentage entrapment efficiency was calculated by the following equation [28-30].

$$
\% E E=X s-X t X 100
$$

Xs

Where Xs-Total amount of drug used for formulation; Xt-Amount of the drug in $5 \mathrm{ml}$ saline

\section{In vitro drug release}

In vitro drug release refers to the percentage amount of drug release from pellets dispersion which was carried out by the dialysis membrane method. One end of the dialysis membrane was closed or tied tightly, and then $1 \mathrm{ml}$ of pellet dispersion was filled into the dialysis membrane with $0.45 \mu \mathrm{m}$ pore size. After filling the dialysis membrane, both their ends were tied tightly. Ensure that there is no leakage of pellet dispersion from the tied dialysis membrane. Filled dialysis membrane acts as a donor compartment. Then the filled dialysis membrane was immersed into a $100 \mathrm{ml} \mathrm{pH} \mathrm{7.4} \mathrm{Phosphate} \mathrm{Buffer} \mathrm{Solution,} \mathrm{which} \mathrm{was} \mathrm{kept} \mathrm{in} \mathrm{a}$ magnetic stirrer at $100 \mathrm{rpm}$. The $5 \mathrm{ml}$ of the sample was collected from the phosphate buffer solution phase at regular intervals of $0,1,2,4,6,8$, $10,12 \mathrm{~h}$. Then the same $5 \mathrm{ml}$ with fresh PBS solution in the receptor compartment was replaced to maintain a sinking condition. The released drug absorbance at each time interval was measured by using UV Spectrophotometer at $240 \mathrm{~nm}$ for Carvedilol. The experiment was carried out in triplicate $(\mathrm{n}=3)[31,32]$.

\section{RESULTS AND DISCUSSION}

\section{Drug and excipients compatibility studies}

The following melting points were observed as endothermic peak readings in DSC thermogram as shown in fig. 1; Carvedilol at $114.49^{\circ} \mathrm{C}$; Physical mixture(mixture of drug and excipients) thermogram shows reproducibility in thermogram peak at $116.40^{\circ} \mathrm{C}$ (Drug peak). From the data, it was inferred that on performing the DSC studies for pulsatile formulation, which ensures that the drug was effectively miscible in physical mixture. This thermal behavior confirms that both drugs exist in an amorphous form or molecularly dispersed in nature and also the excipients used in the formulation like polyvinyl pyrrolidone, Aerosil, Ethylcellulose EC7 CPS, Kollicoat SR 30 D, Eudragit L 100, Di-octyl-phthalate (DOP) \%, Isopropyl alcohol are highly compatible to the drug i.e., the drug property will not be affected by the excipients used in the pulsatile formulation [10-12].

\section{Screening of CMA for optimization technique}

A trial formulation of pellets was shown in table 3. From the trial formulation data it shows that all the pellet sizes attained micron size range from $6818.1 \pm 46.8 \mathrm{~nm}$ to $1247.4 \pm 6.4 \mathrm{~nm}$. Among nine formulations, P1 carvedilol pulsatile pellet shows better reduces the particle size of about $1247.4 \pm 6.4 \mathrm{~nm}$. From the data it was concluded that Ethylcellulose EC7 CPS polymer was selected as a best and suitable polymer for the formulation of pulsatile pellets. So, Ethylcellulose EC7 CPS polymer was used to optimize the carvedilol pulsatile pellets $[13,14]$.

Table 3: Screening of CMA for optimization technique

\begin{tabular}{|c|c|c|c|c|c|c|c|c|c|}
\hline Parameter & P1 & P2 & P3 & P4 & P5 & P6 & P7 & P8 & P9 \\
\hline Particle Size (nm) & $1247.4 \pm 6.4$ & $\begin{array}{l}1311.6 \\
\pm 5.8\end{array}$ & $\begin{array}{l}1734.0 \\
\pm 7.6\end{array}$ & $1853.4 \pm 10.3$ & $\begin{array}{l}2264.2 \\
\pm 16.8\end{array}$ & $2725.1 \pm 19.2$ & $2147.0 \pm 14.6$ & $3051.5 \pm 28.6$ & $6818.1 \pm 46.8$ \\
\hline
\end{tabular}

All the values are shown in mean \pm SD: $n=3$ 


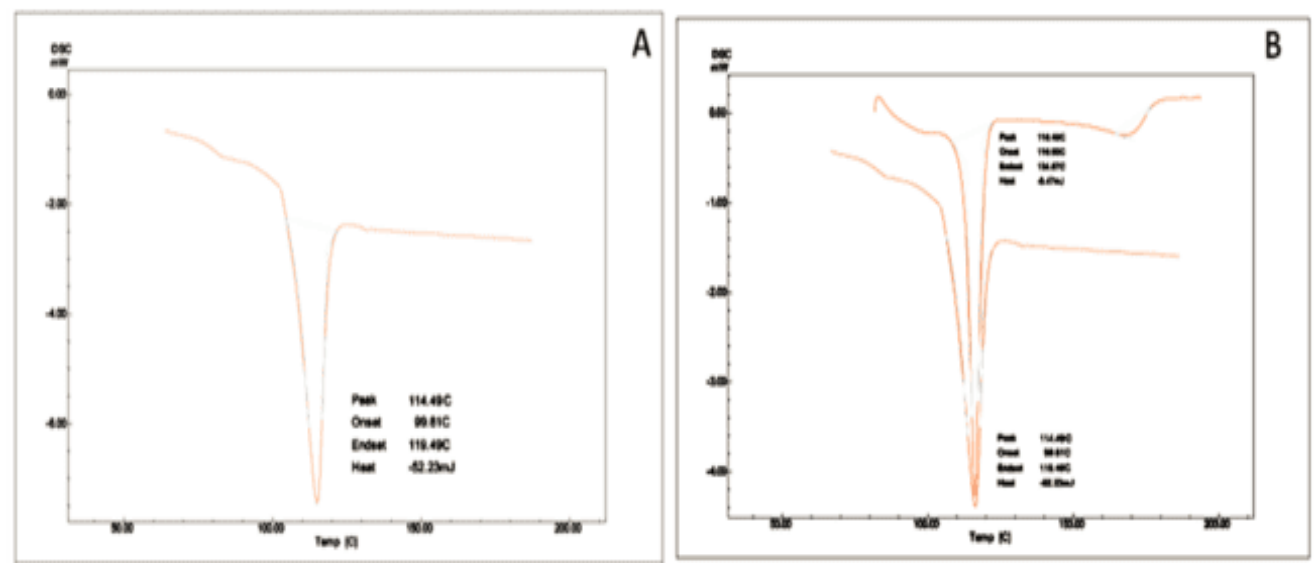

Fig. 1: DSC Thermogram; (A) Carvedilol; (B) Overlap thermogram of carvedilol and physical mixture

Table 4: Optimization of carvedilol pulsatile drug delivery tablet by QbD

\begin{tabular}{|c|c|c|c|c|c|c|c|}
\hline \multirow[t]{2}{*}{ Run } & \multicolumn{4}{|c|}{$\begin{array}{l}\text { Critical material attributes (CMA) and critical process parameter } \\
\text { (CPP) (level/conc. or range) }\end{array}$} & \multicolumn{3}{|c|}{ Critical quality attribute (CQA) } \\
\hline & Pattern & $\begin{array}{l}\text { Conc. of EC } \\
\text { (mg) }\end{array}$ & $\begin{array}{l}\text { Inlet temperature } \\
\left({ }^{\circ} \mathrm{C}\right)\end{array}$ & $\begin{array}{l}\text { Atomizing air } \\
\text { pressure }\left(\mathrm{kg} / \mathrm{cm}^{2}\right)\end{array}$ & Particle size (nm) & $\begin{array}{l}\text { Entrapment } \\
\text { efficiency \% }\end{array}$ & $\begin{array}{l}\% \text { amt. of drug } \\
\text { release at } 12 \mathrm{~h}\end{array}$ \\
\hline CP1 & $0-+$ & $0 / 5$ & $-1 / 40$ & $1 / 1.5$ & $1619.1 \pm 12.4$ & $75.6 \pm 2.4$ & $72.4 \pm 2.6$ \\
\hline CP2 & ++0 & $1 / 7.5$ & $1 / 45$ & $0 / 1$ & $2814.9 \pm 22.6$ & $43.2 \pm 2.2$ & $38.4 \pm 2.8$ \\
\hline CP3 & $0++$ & $0 / 5$ & $1 / 45$ & $1 / 1.5$ & $1925.2 \pm 20.6$ & $60.4 \pm 3.4$ & $65.4 \pm 2.6$ \\
\hline $\mathrm{CP} 4$ & $0+-$ & $0 / 5$ & $1 / 45$ & $-1 / 0.5$ & $1258.4 \pm 10.4$ & $98.5 \pm 2.8$ & $78.5 \pm 2.8$ \\
\hline CP 5 & +-0 & $1 / 7.5$ & $-1 / 40$ & $0 / 1$ & $3378.4 \pm 24.2$ & $36.4 \pm 4.6$ & $35.6 \pm 2.4$ \\
\hline $\mathrm{CP} 6$ & $+0+$ & $1 / 7.5$ & $0 / 43$ & $1 / 1.5$ & $2535.5 \pm 20.4$ & $62.6 \pm 3.4$ & $60.4 \pm 2.8$ \\
\hline $\mathrm{CP} 7$ & 000 & $0 / 5$ & $0 / 43$ & $0 / 1$ & $1764.3 \pm 12.6$ & $78.4 \pm 3.8$ & $65.2 \pm 2.6$ \\
\hline СР 8 & 000 & $0 / 5$ & $0 / 43$ & $0 / 1$ & $1765.1 \pm 16.4$ & $79.8 \pm 3.2$ & $66.8 \pm 2.6$ \\
\hline СР 9 & $-0+$ & $-1 / 2.5$ & $0 / 43$ & $1 / 1.5$ & $1136.8 \pm 10.6$ & $82.4 \pm 2.6$ & $79.4 \pm 2.8$ \\
\hline CP 10 & $0--$ & $0 / 5$ & $-1 / 40$ & $-1 / 0.5$ & $1929.4 \pm 12.8$ & $64.6 \pm 3.2$ & $68.4 \pm 2.4$ \\
\hline CP 11 & -+0 & $-1 / 2.5$ & $1 / 45$ & $0 / 1$ & $1232.9 \pm 12.4$ & $89.4 \pm 2.6$ & $79.6 \pm 2.8$ \\
\hline CP 12 & $+0-$ & $1 / 7.5$ & $0 / 43$ & $-1 / 0.5$ & $2823.3 \pm 24.6$ & $56.4 \pm 2.4$ & $34.2 \pm 2.8$ \\
\hline CP 13 & --0 & $-1 / 2.5$ & $-1 / 40$ & $0 / 1$ & $1017.5 \pm 10.2$ & $96.8 \pm 2.2$ & $88.4 \pm 2.8$ \\
\hline CP 14 & $-0-$ & $-1 / 2.5$ & $0 / 43$ & $-1 / 0.5$ & $1128.5 \pm 14.8$ & $93.4 \pm 2.6$ & $80.6 \pm 2.6$ \\
\hline CP 15 & 000 & $0 / 5$ & $0 / 43$ & $0 / 1$ & $1836.1 \pm 15.4$ & $66.4 \pm 3.4$ & $75.4 \pm 2.4$ \\
\hline
\end{tabular}

All the values are shown in mean \pm SD: $n=3$

\section{Particle size}

The particle size of pulsatile pellets was in the range of $1017.5 \pm 10.2$ $\mathrm{nm}$ to $2823.3 \pm 24.6 \mathrm{~nm}$. All the formulation was within the range of 1 to $3 \mathrm{~mm}$ base on the concentration of polymer and effect of process parameter. The concentration of polymer and process parameter was shows the significant change in particle size. On decreasing in EC polymer concentration, controlled inlet temperature and controlled atomizing air pressure plays a vital role in decrease in particle size. The thickness of EC coat was maximum controlled by inlet temperature and atomizing air pressure. The polymer coat was not uniform throughout the particle on increasing the inlet temperature and atomizing air pressure; this may be due to accumulation of polymers to particular group of pellets. This effect resulting in agglomeration of particles, leads to missing of uniformity in coating of polymers. So the Inlet temperature and atomizing air pressure should be controlled and optimized manner [16-19].

\section{Entrapment efficiency}

The \% EE of the pulsatile pellets was found to be in the range of $43.2 \pm 2.2$ to $98.5 \pm 2.8 \%$. The entrapment efficiency of the pellets is based on the concentration of polymer and thickness of the polymer coat. The thickness of the polymer coat was controlled by process parameters like during inlet temperature and the atomization air pressure. Even though the concentration of polymer is reduced; the coating will be done perfectly by controlling the process like inlet temperature and atomizing air pressure [20-24].

\section{Amount of drug release}

The $\%$ amount of drug release was found to be in the range of $34.2 \pm 2.8$ to $88.4 \pm 2.8 \%$ at $12 \mathrm{~h}$. The variation in drug release between the formulations was purely based on the concentration of EC polymer and thickness of the polymer coat. The uniformity of cumulative amount of drug release will be significantly based on the uniformity of drug coating $[25,26]$.

\section{Optimization of carvedilol pulsatile drug delivery system by} box-behnken design

The box-behnken optimization design and its data was shown in table 4-7 and fig. 2-4, which reveals the effect of CMA, CPP on CQA during the preparation of carvedilol pulsatile pellets. From the data obtained, it was concluded that there was a strong correlation between the CQA-like particle size, entrapment efficiency, \% drug release with CMA and CPP-like polymer concentration, inlet temperature and atomization pressure. It was observed that there was a strong correlation that was established between polymer concentration vs. particle size of pellets $\left(r^{2}=0.98\right)$ as shown in the prediction plot. It shows that there was an increase in pellet particle size by increasing the EC polymer concentration from- 1 to 0 levels, i.e., from $1017.5 \pm 10.2 \mathrm{~nm}$ to $1929.4 \pm 12.8 \mathrm{~nm}$, at the same time from 0 to +1 levels, there was an increase in particle size i.e., from $1258.4 \pm 10.4 \mathrm{~nm}$ to $3378.4 \pm 24.2 \mathrm{~nm}$. The change in inlet temperature and atomization pressure from 0 to- 1 level there was a decrease in particle size, increase in entrapment efficiency from $36.4 \pm 4.6 \%$ to $93.4 \pm 2.6 \%$ and $\%$ amount of drug release from 
$35.6 \pm 2.4 \%$ to $88.4 \pm 2.8 \%$. From 0 to +1 level of CMA and CPP, it shows there was an increase in particle size from $1258.4 \pm 10.4 \mathrm{~nm}$ to $3378.4 \pm 24.2 \mathrm{~nm}$; decrease in entrapment efficiency and \% amount of drug release. This may be due to the optimum reduction of polymer concentration. Further increasing in 0 to +1 level, there was an increase in particle size. This effect may be due to more loading of polymer-coated over the drug coat and extreme drying of polymer coat by inlet temperature. Fig. 2 shows the prediction plot, it shows there was significant changes on CQA based on CMA and CPP i.e., RSq value of the effect of attribute vs. particle size shows 0.98 ; the RSq value of attribute vs. entrapment efficiency shows 0.89 ; the RSq value of attributes vs. \% drug release shows 0.93 , which mean that there was a significant changes in CQA on changes in CMA and CPP. On executing the polymer concentration vs. PS in ANOVA, the ' $\mathrm{P}$ ' value was found to be $<0.05$, which confirmed that there was a significant difference in PS by increasing the concentration of polymer and also when $\mathrm{P}<0.05$, the effect of inlet coating temperature and atomization pressure on PS, showed a significant difference in PS. Among all formulations (CP1-CP15), the CP13 formulation showed a required particle size of about $1017.5 \pm 10.2$ $\mathrm{nm}$, good entrapment efficiency of about $96.8 \pm 2.2 \%$ and $88.4 \pm 2.8 \%$ amount of drug release at $12 \mathrm{~h}$ at the low- 1 level of EC coating polymer concentration. Increased inlet coating temperature from-1 to 0 levels, it was found to decrease in particle size and increase in entrapment efficiency. Further increasing inlet temperature and atomizing pressure after 0 level, there was an increase in particle size ( $r^{2}=-0.843$ negative linear regression) and decrease in entrapment efficiency, $\%$ amount of drug release. It may be due to the effect of increasing polymer concentration through more atomizing pressure, which will lead to loads of more polymer solution through atomization pressure. By establishing itself in ANOVA, when $\mathrm{P}$ value was found to be 0.0245 , it showed a significant change in PS, EE and \% ADR by decreasing the polymer concentration and increases in the inlet coating temperature and atomizing pressure from 0 to-1level. It also confirmed that, there was a significant change in PP by increasing the atomization pressure with $P$ value $<0.05$. Decrease atomization pressure at 0 levels during the preparation of pellets shows a simultaneous desired decrease in PS, increase in \% EE and increase in \% ADR. Among all Carvedilol pulsatile pellet formulations (CP1-CP15), CP13 formulation shows an expected $\% \mathrm{EE}$ of about $96.8 \pm 2.2 \%$ of the low1 level $\left(40{ }^{\circ} \mathrm{C}\right.$ of inlet temperature) and moderate 0 levels (1 $\mathrm{kg} / \mathrm{cm}^{2}$ ) of Atomizing air Pressure. Among all Carvedilol CP13 formulations showed more $\%$ ADR of about $88.4 \pm 2.8 \%$ at moderate 0 levels $\left(1 \mathrm{~kg} / \mathrm{cm}^{2}\right.$ of Atomizing air pressure). Prediction plot (fig. 2 A) shows that there is a significant enhancement of particle size of pellets with an increase in the concentration of critical material attributes like EC levels. So that it shows a good regression value of 0.98. The CMA, CPP effect on entrapment efficiency (fig. 2B) also shows a good linear regression values of about $0.89 ; \%$ amount of drug release of about 0.93 . From the prediction plot it was confirmed that on change in CMA (EC concentration) and CPP (Inlet temperature, Atomizing air Pressure) there will be a significant change in CQA like Particle size $(\mu \mathrm{m})$, Entrapment efficiency $(\%), \%$ amount of drug release (ADR) $[23,24]$. From the optimization data, it was concluded that CP13 was the optimized formulation. The polynomial equations were derived from the coefficient table 5-7 is as follows, which shows which CMA and CPP was significant parameter towards CQA [22-27].

$$
P S=1788.5+892.888 \times 1 \ldots . . . \text { Equation (1) }
$$

$\% E E=81.533-17.925 X_{1}-9.775 X_{2} X_{3} \ldots . . .$. Equation (2)

$\% A D R=69.13-19.65 X_{1} \ldots . .$. Equation $(3)$

Where, $\mathrm{X} 1=$ Polymer Concentration; $\mathrm{X} 2=$ Inlet temperature; $\mathrm{X} 3=$ Atomizing air pressure
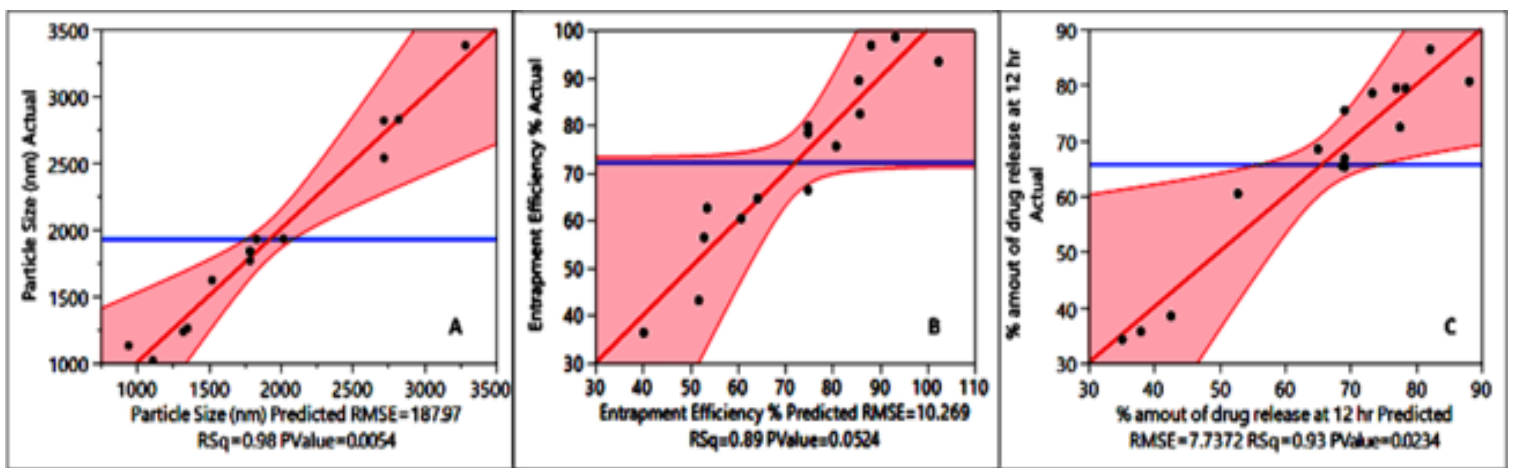

Fig. 2: Prediction plot shows Rsq based on the response of CMA, CPP on CQA like (A) Particle size ( $\mu \mathrm{m})$; (B) Entrapment efficiency (\%); (C) $\%$ amount of drug release (ADR)
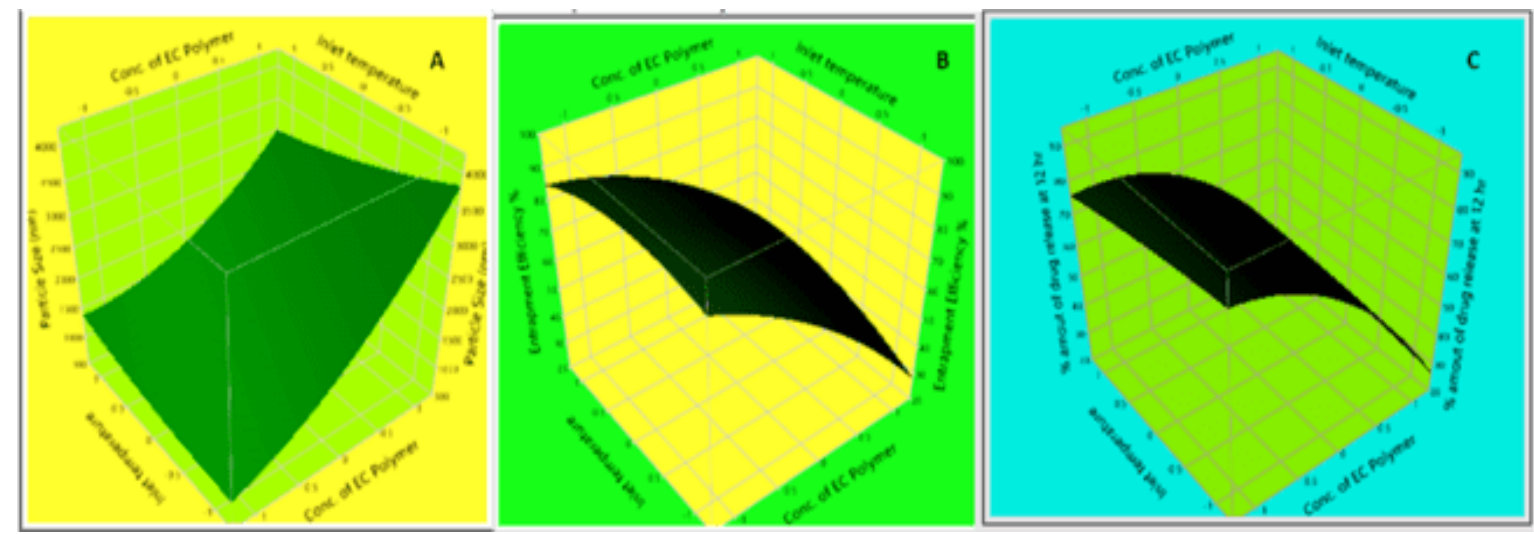

Fig. 3: Response surface profiler graph showing the relation between CMA, CPP Vs. CQA; (a) CMA, CPP Vs. Particle size; (b) CMA, CPP Vs. \% Entrapment efficiency; (c) CMA, CPP Vs. \% Amount of drug release effect summary 


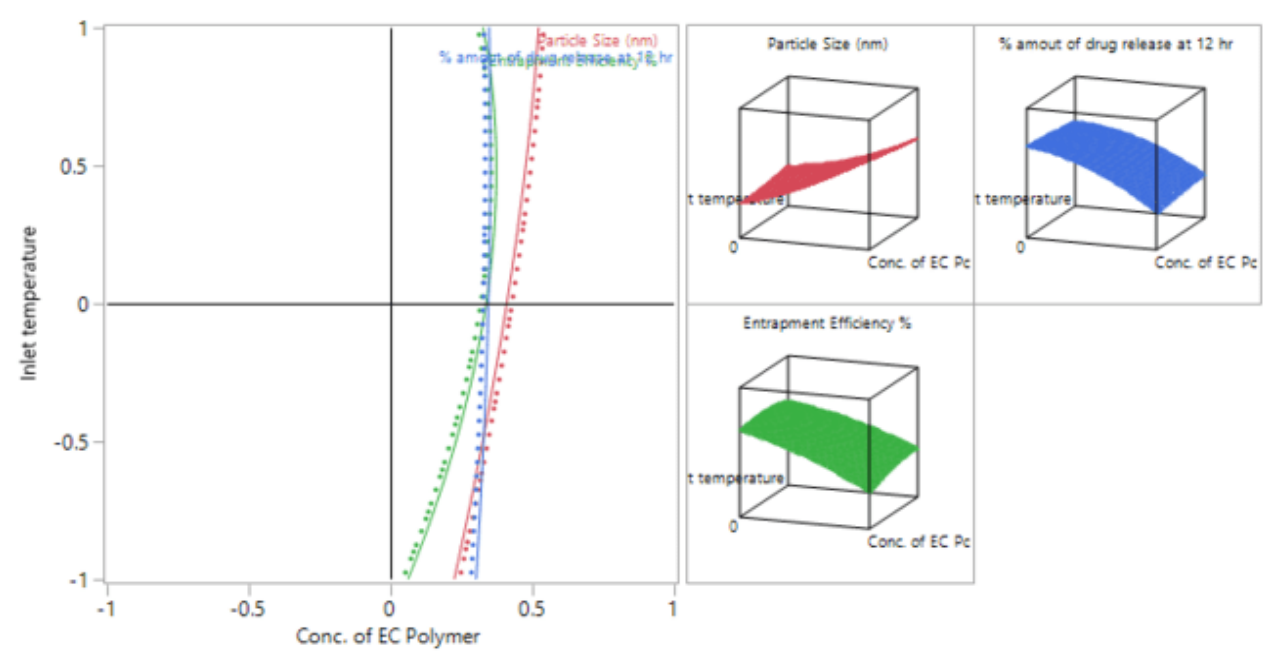

Fig. 4: Contour profiler graph showing the relation between CMA, CPP Vs. CQA

Table 5: Coefficient table shows parameters estimates of CMA, CPP on particle size

\begin{tabular}{|c|c|c|c|c|}
\hline Term & Estimate & Std error & t Ratio & Prob $>\mid t$ \\
\hline Intercept & 1788.5 & 108.5261 & 16.48 & $<.0001^{*}$ \\
\hline Conc. of EC Polymer & 892.8875 & 81.3946 & 10.97 & $0.0004^{*}$ \\
\hline Inlet temperature & -89.125 & 66.45841 & -1.34 & 0.2510 \\
\hline Atomizing air pressure & -3.7125 & 81.3946 & -0.05 & 0.9658 \\
\hline Conc. of EC Polymer*Inlet temperature & -194.725 & 93.98639 & -2.07 & 0.1070 \\
\hline Conc. of EC Polymer*Atomizing air pressure & -47.35 & 132.9168 & -0.36 & 0.7397 \\
\hline Inlet temperature*Atomizing air pressure & 244.275 & 93.98639 & 2.60 & 0.0601 \\
\hline Conc. of EC Polymer*Conc. of EC Polymer & 259.375 & 108.5261 & 2.39 & 0.0752 \\
\hline Inlet temperature*Inlet temperature & 63.05 & 108.5261 & 0.58 & 0.5924 \\
\hline Atomizing air pressure*Atomizing air pressure & -168.525 & 108.5261 & -1.55 & 0.1954 \\
\hline
\end{tabular}

Table 6: Coefficient table shows parameters estimates of CMA, CPP on \% entrapment efficiency

\begin{tabular}{|c|c|c|c|c|}
\hline Term & Estimate & Std Error & t Ratio & Prob $>|t|$ \\
\hline Intercept & 81.533333 & 4.387362 & 18.58 & $<.0001^{*}$ \\
\hline Conc. of EC Polymer & -17.925 & 2.686699 & -6.67 & $0.0011^{*}$ \\
\hline Inlet temperature & 1.0125 & 2.686699 & 0.38 & 0.7217 \\
\hline Atomizing air pressure & -5.2375 & 2.686699 & -1.95 & 0.1088 \\
\hline Conc. of EC Polymer*Inlet temperature & 3.55 & 3.799567 & 0.93 & 0.3930 \\
\hline Conc. of EC Polymer*Atomizing air pressure & 4.3 & 3.799567 & 1.13 & 0.3091 \\
\hline Inlet temperature*Atomizing air pressure & -9.775 & 3.799567 & -2.57 & $0.0499 *$ \\
\hline Conc. of EC Polymer*Conc. of EC Polymer & -6.829167 & 3.954715 & -1.73 & 0.1448 \\
\hline Inlet temperature*Inlet temperature & -3.254167 & 3.954715 & -0.82 & 0.4480 \\
\hline Atomizing air pressure*Atomizing air pressure & -1.004167 & 3.954715 & -0.25 & 0.8097 \\
\hline
\end{tabular}

Table 7: Coefficient table shows parameters estimates of CMA, CPP on \% amount of drug release

\begin{tabular}{|c|c|c|c|c|}
\hline Term & Estimate & Std error & t Ratio & $\operatorname{Prob}>|\mathbf{t}|$ \\
\hline Intercept & 69.133333 & 4.467058 & 15.48 & $<.0001^{*}$ \\
\hline Conc. of EC Polymer & -19.65 & 2.735503 & -7.18 & $0.0008^{*}$ \\
\hline Inlet temperature & -0.1375 & 2.735503 & -0.05 & 0.9619 \\
\hline Atomizing air pressure & 1.9875 & 2.735503 & 0.73 & 0.5001 \\
\hline Conc. of EC Polymer*Inlet temperature & 2.45 & 3.868586 & 0.63 & 0.5544 \\
\hline Conc. of EC Polymer*Atomizing air pressure & 6.85 & 3.868586 & 1.77 & 0.1368 \\
\hline Inlet temperature*Atomizing air pressure & -4.275 & 3.868586 & -1.11 & 0.3195 \\
\hline Conc. of EC Polymer*Conc. of EC Polymer & -8.354167 & 4.026552 & -2.07 & 0.0927 \\
\hline Inlet temperature*Inlet temperature & -0.829167 & 4.026552 & -0.21 & 0.8450 \\
\hline Atomizing air pressure*Atomizing air pressure & 2.8708333 & 4.026552 & 0.71 & 0.5077 \\
\hline
\end{tabular}

\section{Scanning electron microscopy}

Surface morphology and shape of optimized carvedilol pulsatile pellets were observed for SEM studies as shown in fig. 5 . The study revealed that the carvedilol pulsatile pellets were mostly spherical in shape; the particle surface had a distinctive smoothness, and the particle size, as shown by SEM, was in the micrometric range. 


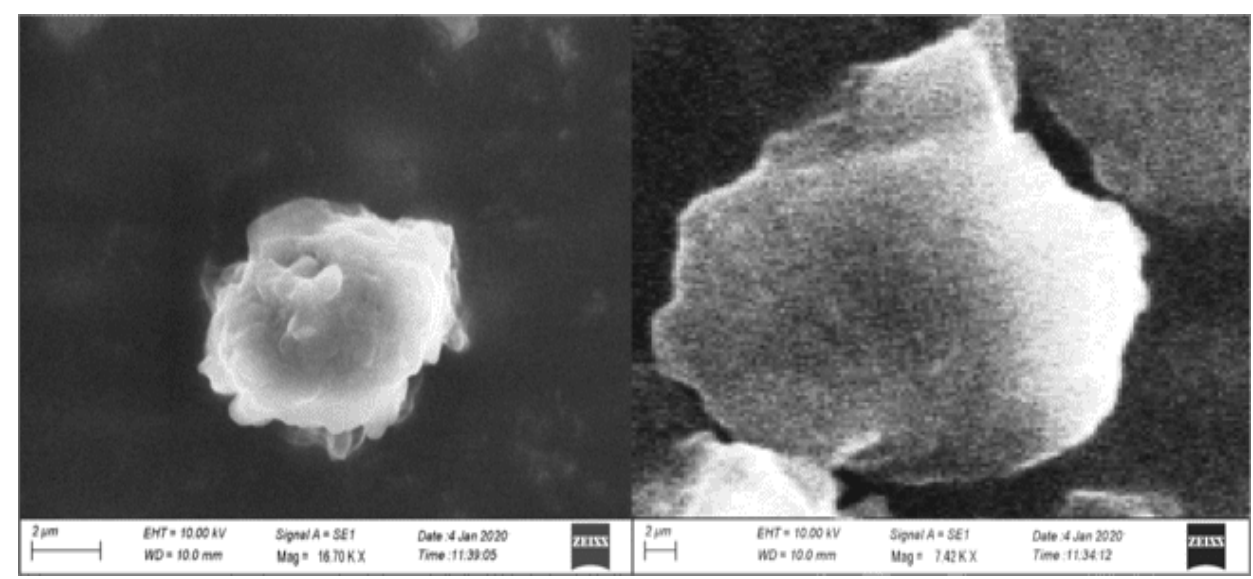

Fig. 5: SEM images of optimized CP13 carvedilol pulsatile pellet

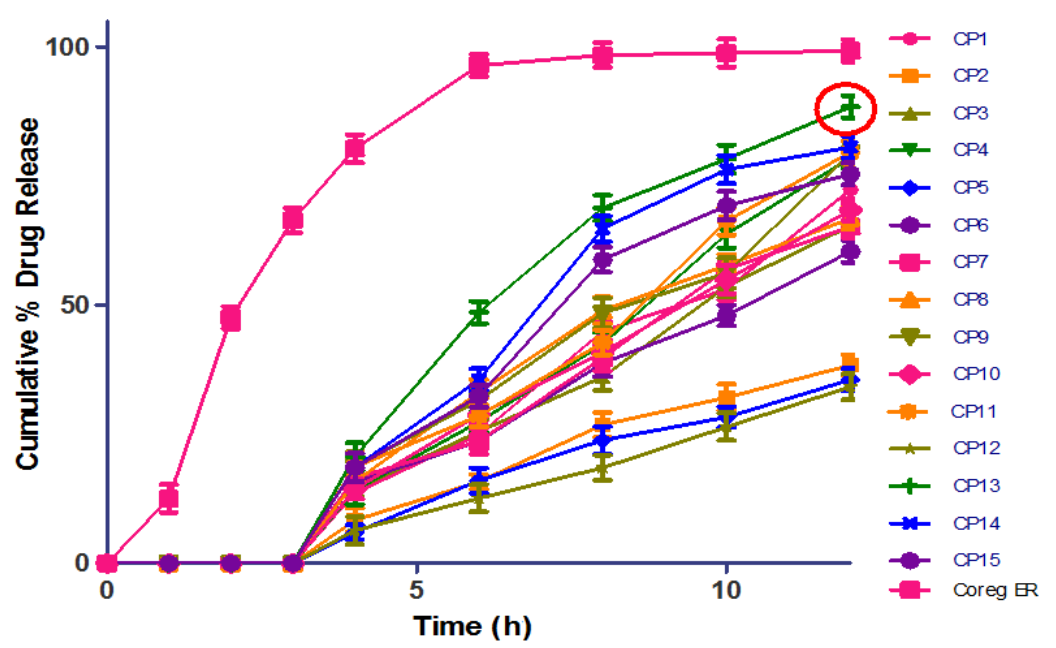

Fig. 6: Comparative in vitro drug release study profile of carvedilol pulsatile pellets Vs. marketed coreg $\mathrm{ER}^{\circledR}(\mathrm{mean} \pm S D$ : $n=3)$

\section{In vitro drug release}

The drug release profile for Carvedilol pulsatile pellets was investigated in phosphate buffer ( $\mathrm{pH}$ 7.4) by packing in a gelatin capsule. It shows that particle size decreased, the surface area increased, allowing more dissolution of the drug from the pellets. The release of drugs from the pellets mainly depends on polymer concentration. When the concentration of polymer increased with the formulation resulted in smaller micron-sized particles were formed, this resulted in the enhancement of the dissolution profile of carvedilol. Thus, the carvedilol release from CP13 Pulsatile pellets was found to be higher $(88.4 \pm 2.8 \%)$ at $12 \mathrm{~h}$ than other formulations and marketed Coreg-ER tablets as shown in fig. 6. With an increase in the polymer concentration in CP13, the release of the drug was controlled well leads to a cumulative increase in the percentage amount of drug release, and the successful distribution of the drug is partly due to the size of the microparticles and the viscosity of the polymers, which makes for a higher rate of drug release into the aqueous medium.

\section{CONCLUSION}

From the research data, it was concluded that Carvedilol Pulsatile drug delivery system was designed by using optimized fluidized bed coater in order to decrease the usage of attributes, decrease the productivity cost and enhance the usage of specific attributes at fixed concentration like- 1 level or $2.5 \mathrm{mg}$ of EC concentration; -1 level or $40{ }^{\circ} \mathrm{C}$ of inlet temperature; 0 level or $1 \mathrm{~kg} / \mathrm{cm}^{2}$ of atomizing air pressure for further manufacturing scale. By the current results it was concluded that the optimized CMA and CPP that shown in the results are the suitable attributes for the best formulation of carvedilol pulsatile drug delivery system capsules.

\section{FUNDING}

There is no funding for this project.

\section{AUTHORS CONTRIBUTIONS}

All the authors are involved in the review of literature, collection of data and preparation of the manuscript and also they were involved in reviewing and editing of the manuscript.

\section{CONFLICT OF INTERESTS}

There is no conflict of interest for this research

\section{REFERENCES}

1. Vuppala MK, Parikh DM, Bhagat HR. Application of powderlayering technology and film coating for manufacture of sustained-release pellets using a rotary fluid bed processor. Drug Dev Ind Pharm. 1997;23(7):687-94. doi: 10.3109/03639049709150770.

2. Zimm KR, Schwartz JB, O'Connor RE. Drug release from a multiparticulate pellet system. Pharm Dev Technol. 1996;1(1):37-42. doi: 10.3109/10837459609031416, PMID 9552329.

3. Pearnchob Nantharat, Bodmeier Roland. Dry powder coating of pellets with micronized Eudragit RS for extended drug release. Pharm Res. 2003;20(12):1970-6. doi: 10.1023/ b:pham.0000008044.78968.81, PMID 14725361. 
4. Shinde AKJ, Patil NS, Jadhav TS, More HN. Design and development of floating pulsatile drug delivery of losartan potassium. Int J Appl Pharm. 2020;12:218-27. doi: 10.22159/ijap.2020v12i4.37607.

5. Wong TW, Cheong WS, Heng PWS. Melt granulation and pelletization. In: Parikh DM, editor. Handbook of pharmaceutical granulation technology. Taylor and Francis group; 2005. p. 385-406.

6. Ahir Amita A, Mali Sachin S, Hajare Ashok A, Bhagwat Durgacharan A, Patrekar Prasad V. Pelletization technology: methods and applications a review. Res J Pharm Technol. 2015;8(2):131-8. doi: 10.5958/0974-360X.2015.00023.2.

7. Atilla HA, Suheyla KH. Preparation of micropellets by spraying congealing. In: Ghebre-sellassie I, editor. Multiparticulate oral drug delivery. New York: Marcel Dekker Inc; 1994. p. 17-34.

8. Ratul Deb, Baquee Ahmed Abdul. Pellet and pelletization technique: A critical review. Int Res J Pharm. 2013;4:90-5.

9. Trivedi Namrata R, Rajan Maria Gerald, Johnson James R, Shukla Atul J. Pharmaceutical approaches to preparing pelletized dosage forms using the extrusion-spheronization process. Crit Rev Ther Drug Carrier Syst. 2007;24(1):1-40. doi: 10.1615/ critrevtherdrugcarriersyst.v24.i1.10, PMID 17430098.

10. Singh Bhupinder, Dahiya Manju, Saharan Vandana, Ahuja Naveen. Optimizing drug delivery systems using systematic "design of experiments." Part II: retrospect and prospects. Crit Rev Ther Drug Carrier Syst. 2005;22(3):215-94. doi: 10.1615/critrevtherdrugcarriersyst.v22.i3.10, PMID 15896189.

11. Lewis GA, Mathieu D, Phan-Tan-Luu R. Pharmaceutical experimental design. New York: Marcel Dekker; 1999.

12. Singh B, Ahuja N. Pharmaceutical experimental design (Drugs and the Pharmaceutical Sciences, Vol. 92), Edited by GA Lewis, D. Mathieu and R. Phan-Tan-Luu, 1st Edition, Marcel Dekker, New York. International Journal of Pharmaceutics. 2000;195(12):247-8. doi: 10.1016/S0378-5173(99)00384-1.

13. Celik M, Wendel SC. Spray drying and pharmaceutical applications. In: Parikh DM, editor. Handbook of pharmaceutical granulation technology. Taylor \& Francis Group; 2005. p. 129.

14. Bijapur Bharat, Gowda DV, Vishal Gupta N, Shailesh Thirumaleshwar, Praveen Sivadasu, Manjunath M. Formulation and investigation of polymeric multiple-unit pellet systems consisting of sustained-release glimepiride and immediate release atorvastatin calcium. Asian J Pharm Clin Res. 2019;12:142-50.

15. Harrison PJ, Newton JM, Rowe RC. Convergent flow analysis in the extrusion of wet powder masses. J Pharm Pharmacol. 1984;36(12):796-8. doi: 10.1111/j.2042-7158.1984.tb04879.x, PMID 6151969.

16. Steckel H, Mindermann Nogly F. Production of chitosan pellets by extrusion/spheronization. Eur J Pharm Biopharm. 2004;57(1):10714. doi: 10.1016/s0939-6411(03)00156-5. PMID 14729086.

17. bach Breiten. From process to drug delivery technology. Eur J Biopharm Melt Extrusion. 2002;54:107-17.

18. Gandhi R, Lal Kaul C, Panchagnula R. Extrusion and spheronization in the development of oral controlled-release dosage forms. Pharm Sci Technol Today. 1999;2(4):160-70. doi: 10.1016/S1461-5347(99)00136-4.

19. Cheboyina Sreekhar, Wyandt Christy M. Wax-based sustained release matrix pellets prepared by a novel freeze pelletization technique I. Formulation and process variables affecting pellet characteristics. Int J Pharm. 2008;359(1-2):158-66. doi: 10.1016/j.ijpharm.2008.04.011. PMID 18499369.

20. Cheboyina Sreekhar, Wyandt Christy M. Wax-based sustained release matrix pellets prepared by a novel freeze pelletization technique II. In vitro drug release studies and release mechanisms. Int J Pharm. 2008;359(1-2):167-73. doi: 10.1016/j.ijpharm.2008.04.001. PMID 18495391.

21. Kovacevic Jovana, Mladenovic Aleksandar, Djuris Jelena, Ibric Svetlana. Evaluation of powder, solution and suspension layering for the preparation of enteric-coated pellets. Eur J Pharm Sci. 2016;85:84-93. doi: 10.1016/j.ejps.2016.01.018, PMID 26796145.

22. Rupam A, Wagh Rajendra K Surawase. Formulation and development of sustained-release pellets of nifedipine by fluidized bed processor. Res J Pharm Technol. 2020;13:1757-61.

23. Rana Hardik B, Gohel Mukesh C, Dholakia Mansi S, Gandh Tejal R, Omri Abdelwahab, Thakkar Vaishali T. Development of sustained-release pellets of galantamine hbr by extrusion spheronization technique incorporating rsk bases QbD approach. Res J Pharm Dev. 2018;11:4899-910.

24. Shravani D, Lakshmi PK, Balasubramaniam J. Preparation and optimization of various parameters of enteric-coated pellets using the Taguchi L9 orthogonal array design and their characterization. Acta Pharmaceutica Sinica B. 2011;1(1):5663. doi: 10.1016/j.apsb.2011.04.005.

25. Rockville MD. Particle size distribution test. NF25. US pharmacopeial convention, inc. United states pharmacopeia; 2012. p. 786.

26. Dukic Ott Aleksandra, De Beer Thomas, Remon Jean-Paul, Baeyens Willy, Foreman Paul, Vervaet Chris. In vitro and in vivo evaluation of enteric-coated starch-based pellets prepared via extrusion/spheronisation. Eur J Pharm Biopharm. 2008;70(1):302-12. doi: 10.1016/j.ejpb.2008.04.019, PMID 18579353.

27. Kuang Chen, Yingua Sun, Bing Li, Rui Fan, Jing Zhang, Yumin Yao, Zhonggui He. Preparation and evaluation of duloxetine hydrochloride enteric-coated pellets with different enteric polymers. Asian J Pharm Sci 2017;12:216-26.

28. Debunne Ann, Vervaet Chris, Mangelings Debby, Remon JeanPaul. Compaction of enteric-coated pellets: influence of formulation and process parameters on tablet properties and in vivo evaluation. Eur J Pharm Sci. 2004;22(4):305-14. doi: 10.1016/j.ejps.2004.03.017, PMID 15196587.

29. Eriksson M, Alderborn G, Nyström C, Podczeck F, Newton JM. Comparison between and evaluation of some methods for the assessment of the sphericity of pellets. International Journal of Pharmaceutics. 1997;148(2):149-54. doi: 10.1016/S03785173(96)04845-4.

30. Surkha Y, Venugopalaiah P, Gnana Prakash K, Gobinath M. Design and characterization of enteric-coated delayed-release pellets of rabeprazole sodium. Res J Pharm Technol. 2013;1:422-34.

31. Senthil Kumar KL, Muthukumaran M, Chenchuratnam B. Formulation and evaluation of rabeprazole enteric coated pellets. Int J Adv Pharm Biol Chem. 2012;1:7-14.

32. Sangram M, Patil Rajesh V, Mishra Satish V, Shirolkar. Development and evaluation of suatained released simvastatin pellets. Res J Pharm Dev. 2017;10:2467-73. 